\title{
Place and health infrastructure in the Gulf Cooperation Council: A systematic scoping review of GIS applications in health
}

\author{
Dari Alhuwail, ${ }^{1,2}$ Saad AlSharrah, ${ }^{2,3}$ Neil T. Coffee, ${ }^{2,3}$ Faisal H. Al-Refaei, ${ }^{2}$ Mark Daniel ${ }^{2,3}$ \\ ${ }^{1}$ Department of Information Science, College of Life Sciences, Kuwait University, Safat, Kuwait; ${ }^{2}$ GeoHealth \\ Lab, Dasman Diabetes Institute, Kuwait; ${ }^{3}$ UC Health Research Institute, University of Canberra, Australia
}

\begin{abstract}
The rising burden of non-communicable diseases is taxing health systems globally. Using data science and information systems is necessary to support public health practices. Geographic Information Systems (GIS) are key to inform and help guide public health policies related to place (i.e. location or where one lives) and how it affects health. Despite the increasing use of GIS for public health globally, its applications to health in the Gulf Cooperation Council (GCC) states remains largely unknown. This systematic scoping review aimed to uncover how GIS has been used in the GCC states to understand "place" and "health". A comprehensive search of the literature was performed in PubMed, Scopus, Science Citation Index Expanded, ScienceDirect, Embase, IEEE Xplore, and ACM Digital Library during June 2020. All journal articles involving the use of GIS for human health applications in the GCC states published in English in peerreviewed scientific journals were considered. After removing duplicates and applying eligibility criteria, qualitative content analysis was performed for 24 of 630 studies. GIS uses in the GCC states were categorized as health access and planning $(n=9)$, health risk analysis $(n=8)$, disease surveillance $(n=6)$ and community health profiling $(n=1)$. The majority of the uncovered evi-
\end{abstract}

Correspondence: Dari Alhuwail, Department of Information Science, College of Life Sciences, Kuwait University, P.O. Box 5969, Safat 13060, Kuwait.

E-mail: dari.alhuwail@ku.edu.kw

Key words: Geographic Information Systems; Gulf Cooperation Council; health; place; public health; healthcare; Kuwait; Oman; Kingdom of Saudi Arabia; United Arab Emirates; Bahrain; Qatar.

Conflict of interests: The authors declare no potential conflict of interests.

Received for publication: 17 April 2020.

Accepted for publication: 7 July 2020.

CCopyright: the Author(s), 2020

Licensee PAGEPress, Italy

Geospatial Health 2020; 15:887

doi:10.4081/gh.2020.887

This article is distributed under the terms of the Creative Commons Attribution Noncommercial License (CC BY-NC 4.0) which permits any noncommercial use, distribution, and reproduction in any medium, provided the original author(s) and source are credited. dence in this study focused on the Kingdom of Saudi Arabia. The results of this study indicate a deficiency of published evidence regarding the use of GIS in support of public health in other GCC states. This stands to compromise planning and strategic decision making in health risk analysis, disease surveillance, community health profiling, health services provision and health interventions.

\section{Introduction}

The rising burden of Non-Communicable Diseases (NCDs), such as diabetes and cardiovascular diseases, is exhausting the treatment capacity of health care systems globally (Benziger, 2016). Costs associated with treatment and loss of productivity due to NCDs amount, worldwide, to trillions of dollars annually (Chen et al., 2018). This crisis is affecting many countries globally, including oil-rich nations of the Gulf Cooperation Council (GCC): Bahrain, Kuwait, Oman, Qatar, Saudi Arabia, and the United Arab Emirates.

For the GCC states, this burden is exacerbated by a rising demand for health care services due to sedentary lifestyles (AlHaifi et al., 2013) characterised by high caloric intake coupled with low levels of physical activity, which have led to an increase in the prevalence of chronic diseases such as diabetes (Mattke et al., 2015). The burden on the GCC health care system is further complicated with increasing life expectancy and immense population growth, especially the expatriate workforce (Khoja et al., 2017). This is further aggravated due to challenges associated with climate change including biodiversity loss, desertification, water scarcity, and sea-level rise (Al-Maamary et al., 2017). Additionally, the turbulent oil prices are greatly affecting oil revenues, the main source for financing government expenditures, including health care (Alkhamis, 2017).

Tackling these complex challenges in light of the rising burden of NCDs related to lifestyle necessitates strong and effective public health interventions (Klautzer et al., 2014), for which understanding the environmental factors and context that people live in is essential (Jokar Arsanjani, 2017; Daniel, 2008). Evidence suggests that "place" (i.e. where one lives, works or recreates) affects one's health (Cozier, 2017). Therefore, connecting "place" with "health" is fundamental to understanding the contextual determinants of health care service delivery and vital for effective planning (Dummer, 2008; Cromley and McLafferty, 2011).

Using data science and information systems is a key priority for public health surveillance and tracking (Khoury et al., 2016). Today, informatics tools and systems can support public health professionals and policy makers to characterise and more effectively address the challenge of NCDs via initiatives accounting for 
the contexts in which people live (Sepúlveda, 2014). The evolution of information science and technology has yielded scalable, usable informatics tools to effectively manage and analyse population health data based on disparate sources including health records, disease registries, and administrative datasets (Massoudi and Chester, 2017; Thiébaut and Thiessard, 2017). One of the most popular, and inherently useful, informatics systems available for public health practice are the Geographic Information Systems (GIS), (Fradelos et al., 2014).

GIS is defined as a "computer system with the capacity to capture, store, analyse, and display geographically-referenced information" (Musa et al., 2013). Leveraging GIS to spatially analyse relevant datasets can enable public health professionals to understand the spread of diseases as well as distribution and accessibility of health care services (Dietrich et al., 2018). GIS have aided public health practice via several applications, including disease surveillance, health risk analysis, community health profiling, and health access and planning (Coffee et al., 2012; Nykiforuk and Flaman, 2011). GIS are used to improve health care quality and efficiency through understanding the relationships between the health of the population and the geographic features of their environment (Shaw and McGuire, 2017).

Informed decisions that consider "place" and "health" together are essential for GCC states to continue to operate their health care systems in light of the financial challenges related to the treatment and management of NCDs. Despite the increasing use of GIS for public health globally (Fletcher-Lartey and Caprarelli, 2016; Jia et al., 2017), its application to place and health in the GCC states remains largely unknown. Earlier studies outside the GCC reported the use of GIS in the healthcare domain in 700+ studies (Nykiforuk and Flaman, 2011; Shaw and McGuire, 2017). This systematic scoping review (Arksey and O'Malley, 2005) aimed to uncover how GIS has been used in the GCC states in relation to health. It also aimed to provide high-level policy recommendations to strengthen the use of GIS for public health planning and interventions.

\section{Materials and methods}

\section{Information sources and search strategy}

The purpose of this study was to identify knowledge gaps and uncover potential opportunities to apply GIS for public health purposes in the GCC states by following an approach similar to previous studies (Makanga et al., 2016). A comprehensive search of the literature was performed in the following databases: PubMed, Scopus, Science Citation Index Expanded, ScienceDirect, Embase, IEEE Xplore, and ACM Digital Library. The search for the papers was performed over 3 days in June 2020. The strategy involved the use of the terms (Geographic Information System OR GIS OR Spatial OR Spatiotemporal OR Spatial Analysis;) AND each of the following terms: health care; application; intervention; place and health; neighbourhood and health; non-communicable diseases; exercise; physical activity. To strengthen the search strategy, Medical Subject Headings (MeSH) terms were used in PubMed as well as the use of wildcards (e.g. health*).

\section{Inclusion and exclusion criteria}

Only journal articles published in the English language in peerreviewed scientific journals were considered. Publication date restrictions were not applied. Only studies involving the use of GIS for human health applications in the GCC states were included. Papers that focused on solely environmental issues, remote sensing or development of spatial analysis algorithms were excluded. Both descriptive and comparative studies, either quantitative or qualitative, were included.

\section{Screening process}

At the initial screening, the title and abstract were examined to ensure their compliance with the inclusion criteria previously mentioned. To identify eligible articles, the title and abstract of each article returned were assessed by the researchers. Rayyan, an online application for systematic reviews (Ouzzani et al., 2016), was used to help organize the abstracts. Two independent reviewers assessed each abstract against the inclusion criteria. Disagreements about inclusion were resolved by discussion and consulting a third expert researcher, when necessary. Full-text articles were extracted only for studies meeting the inclusion criteria. Figure 1 illustrates the screening process (Moher et al., 2009).

\section{Evaluation and analysis}

A standardized form was used to extract data items from each of the selected studies, including authors' names, country or geographic region, date of publication, the journal, and how GIS was applied. Two researchers coded the studies after reading the full manuscript. The researchers examined the content of the included studies to identify the categories describing the main use of the GIS application reported. The organization and definition of these categories corresponded to the earlier work of Nykiforuk and Flaman (2011). Four categories of GIS applications were considered for the purposes of organizing this review: i) Health access and planning: Studies that analyse access to health services and delivery for the purposes of planning and policymaking. ii) Disease surveillance: Studies that involve the tracking of data on the incidence, prevalence, and/or spread of disease. It encompasses studies related to disease a) mapping and b) modelling. iii) Risk analysis: Studies that involve some aspect of health risk management, including assessment, communication, and monitoring of risk relative to its impact on health. These studies are typically linked with environmental health. iv) Community health profiling: Studies that map various information regarding the health of a population in a community or geographic location. This often includes health outcomes as well as direct and indirect factors that influence health.

Importantly, these categories are not mutually exclusive, and the applications of GIS are often mixed in the real world. Categorization disagreements between the researchers were resolved via discussion or through consultations with a senior researcher when necessary.

\section{Results}

\section{Overview of included studies}

Initially, 506 articles were identified after removing duplicates, 413 studies were excluded during the screening process based on the titles and abstracts. Out of the remaining 93 studies, articles were assessed for eligibility through a full-text review because they involved the use of GIS for human health applications in the 
GCC. Of these, 24 studies were included in the qualitative synthesis of evidence as depicted in Figure 1.

\section{Qualitative synthesis of evidence}

Overall, all the studies reported using GIS originated from or focused on the Kingdom of Saudi Arabia (KSA), except one in the United Arab Emirates and another one in Kuwait. While there were 20 studies that covered KSA: 11 studies were conducted on the city of Jeddah, one in each of the city of Riyadh and Makkah. At the time of the data collection, the earliest study was published in 2003 and the most recent in 2018. Table 1 presents results for qualitative synthesis of included studies.

\section{Thematic categorization}

Most studies were categorized as health access and planning $(n=9)$, followed by health risk analysis $(n=8)$, disease surveillance $(n=6)$ and one study related to community health profiling. Many of the included studies were not disease specific $(n=9)$; the remainder focused on NCDs, including diabetes $(n=4)$ and cancer $(n=2)$. Other studies focused on Congenital Heart Defects $(n=1)$, Cutaneous leishmaniasis $(n=1)$, exogenous disease mortality $(n=1)$, as well as infectious diseases such as dengue fever $(n=3)$, Middle East respiratory syndrome $(n=2)$.

\section{Health access and planning}

Most studies reported the use of GIS in this topic $(n=9)$. Of these, all but one involved KSA; the remaining one (Yagoub, 2011), involved the United Arab Emirates (UAE). Many studies focused on access to health care facilities. Others focused on health care planning issues, such as defining catchment areas for health care facilities (i.e. hospitals and primary care centres) as well as studying the demand and supply of health services. One study, Yagoub (2011), focused on diabetes and hypertension.

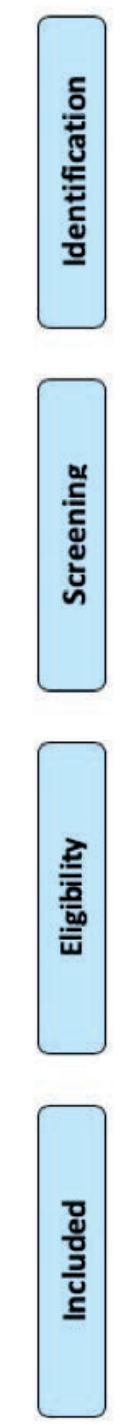

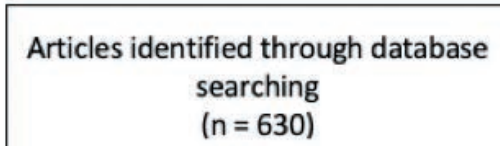

( $n=630$ )
Additional articles identified through other sources $(\mathrm{n}=0)$
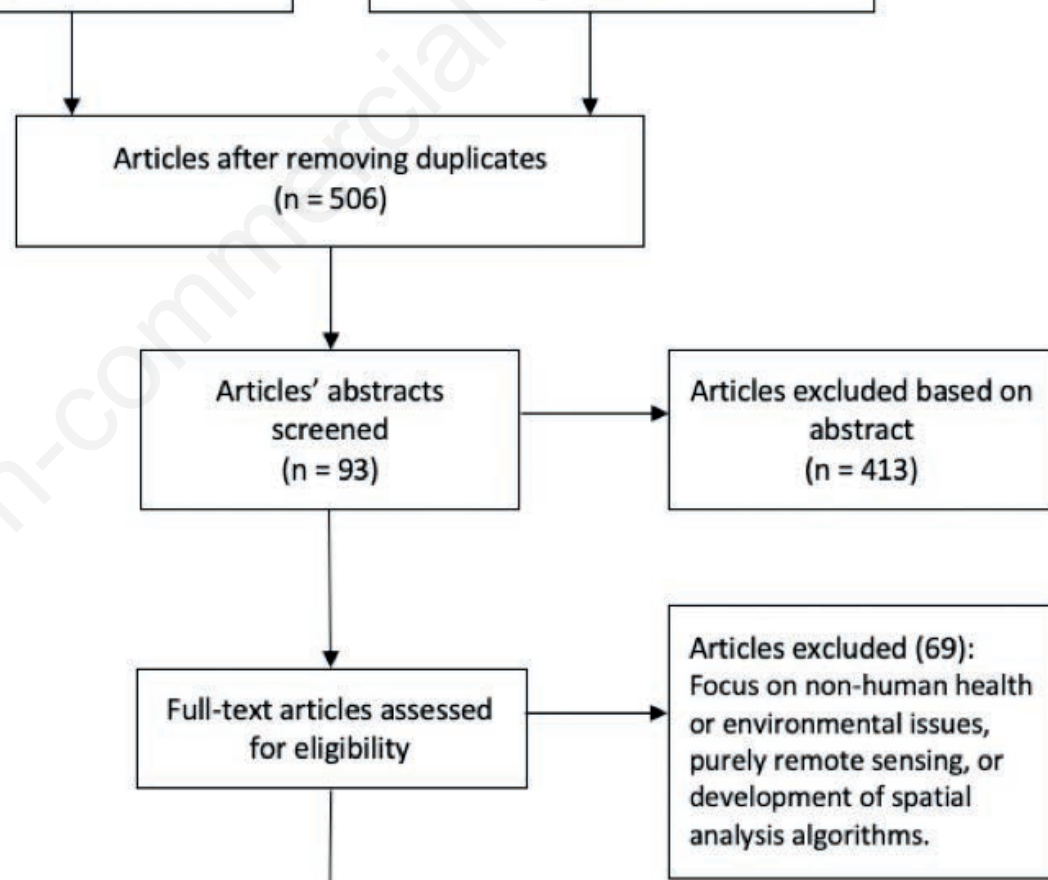

Studies included in qualitative synthesis $(n=24)$

Figure 1. The Preferred Reporting Items for Systematic Reviews and Meta-Analyses (PRISMA) diagram depicting the flow throughout the different phases of the screening and review process. 


\section{Health risk analysis}

Three of the studies in this category focused on assessing and modelling the risk of Dengue fever in Jeddah, KSA. The remaining papers investigated the outbreak of Middle East Respiratory Syndrome, cancer incidence due to exposure to polluted air, spatiotemporal distribution of road traffic crashes, and the climate effects on Cutaneous leishmaniasis.

\section{Disease surveillance}

Most studies in this category focused on NCDs including diabetes and cancer; one study focused on mapping confirmed cases of Dengue fever (Alzahrani et al., 2013). In two of the studies, GIS was used to support a registry system for diabetes (Al-Rubeaan et al., 2013; Subhani, 2009). In another study, the spatial distribution of exogenous disease mortality (e.g. infectious diseases like

\section{Table 1. Summary of included studies.}

\section{No. Author (Year) Location_ Disease-specific Summary of GIS Use}

\section{Health access and planning}

\begin{tabular}{|c|c|c|c|c|}
\hline 1 & Murad (2018) & Jeddah, KSA & $\mathrm{N} / \mathrm{A}$ & Investigated accessibility to health facilities via drive-time analysis technique. \\
\hline 2 & Mansour (2016) & Riyadh, KSA & $\mathrm{N} / \mathrm{A}$ & Assessed geographic variations of service provision and accessibility. \\
\hline 3 & Murad (2014) & Jeddah, KSA & $\mathrm{N} / \mathrm{A}$ & Defined accessibility to health facilities. \\
\hline 4 & Murad (2012) & Jeddah, KSA & N/A & Studied accessibility to health facilities. \\
\hline 5 & Murad (2011) & Jeddah, KSA & N/A & Explored the demand and supply of health services. \\
\hline 6 & Yagoub (2011) & AlAin, UAE & $\begin{array}{l}\text { Diabetes, } \\
\text { hypertension }\end{array}$ & $\begin{array}{l}\text { Assessed the distribution of health facilities and the impact of climate } \\
\text { conditions on health. }\end{array}$ \\
\hline 7 & Murad (2008b) & Jeddah, KSA & $\mathrm{N} / \mathrm{A}$ & Defined health catchment areas. \\
\hline 8 & Murad (2007) & Jeddah, KSA & N/A & Explored the distribution of health demand and defining catchment area. \\
\hline 9 & Murad (2004) & Makkah, KSA & $\mathrm{N} / \mathrm{A}$ & Assessed accessibility to health facilities and patient distribution. \\
\hline \multicolumn{5}{|c|}{ Health risk analysis } \\
\hline 10 & $\begin{array}{l}\text { Jamal et al. } \\
(2019)\end{array}$ & $\begin{array}{l}\text { Eastern Province, } \\
\text { KSA }\end{array}$ & $\mathrm{N} / \mathrm{A}$ & $\begin{array}{l}\text { Overviewed key descriptive statistics as well as spatial and temporal } \\
\text { distribution for road traffic crashes in the Eastern Province, KSA, from } 2009 \text { to } 2016 .\end{array}$ \\
\hline 11 & $\begin{array}{l}\text { Al-Ahmadi et al. } \\
\text { (2019) }\end{array}$ & KSA & $\begin{array}{l}\text { Middle East } \\
\text { respiratory syndrome }\end{array}$ & $\begin{array}{l}\text { Analysed the spatiotemporal patterns and clusters of laboratory-confirmed } \\
\text { MERS-CoV cases reported in KSA between June } 2012 \text { and March } 2019 .\end{array}$ \\
\hline 12 & $\begin{array}{l}\text { Adegboye et al. } \\
(2017)\end{array}$ & KSA & $\begin{array}{l}\text { Middle East } \\
\text { respiratory syndrome }\end{array}$ & Conducted retrospective risk-based analysis of the outbreak. \\
\hline 13 & $\begin{array}{l}\text { Jaber et al. } \\
(2013)\end{array}$ & KSA & $\begin{array}{l}\text { Cutaneous } \\
\text { leishmaniasis }\end{array}$ & Studied spatial trends of infection and relationships with climate. \\
\hline 14 & $\begin{array}{l}\text { Al-Ahmadi and } \\
\text { Al-Zahrani (2013a) }\end{array}$ & KSA & Cancer & Conducted spatial analysis of cancer due to air pollution exposure. \\
\hline 15 & $\begin{array}{l}\text { Khormi and } \\
\text { Kumar (2012) }\end{array}$ & Jeddah, KSA & Dengue fever & Assessed risk based on socioeconomic and environmental factors. \\
\hline 16 & $\begin{array}{l}\text { Khormi and } \\
\text { Kumar (2011) }\end{array}$ & Jeddah, KSA & Dengue fever & Modelled risk of infection based on socioeconomic parameters. \\
\hline 17 & Khormi et al. (2011) & Jeddah, KSA & Dengue fever & Modelled risk of infection spatio-temporally. \\
\hline
\end{tabular}

\section{Disease surveillance}

\begin{tabular}{|c|c|c|c|c|}
\hline 18 & $\begin{array}{l}\text { Al-Ahmadi and } \\
\text { Al-Zahrani (2013b) }\end{array}$ & KSA & Cancer & Explored spatial incidence patterns of common cancers in the country. \\
\hline 19 & Alzahrani et al. (2013) & Jeddah, KSA & Dengue fever & Mapped confirmed cases of infection. \\
\hline 20 & Al-Rubeaan et al. (2013) & KSA & Diabetes & Used GIS as a registry system for diabetes. \\
\hline 21 & Subhani (2009) & KSA & Diabetes & Used GIS as a registry system for diabetes. \\
\hline 22 & $\begin{array}{l}\text { Greer et al. } \\
(2005)\end{array}$ & KSA & $\begin{array}{l}\text { Congenital Heart } \\
\text { Defects (CHD) }\end{array}$ & Mapped the geographical distribution of Saudi nationals with the condition. \\
\hline 23 & Aziz (1990) & Kuwait & $\begin{array}{l}\text { Exogenous Disease } \\
\text { Mortality }\end{array}$ & $\begin{array}{l}\text { Mapped spatial distribution of exogenous disease mortality according to the } \\
\text { international classification of diseases among nationals and expatriates to help } \\
\text { reflect the influence of various social, economic, and demographic factors on the } \\
\text { patterns of distribution. }\end{array}$ \\
\hline \multicolumn{5}{|c|}{ Community health profiling } \\
\hline 24 & Murad (2008a) & Jeddah, KSA & Diabetes & $\begin{array}{l}\text { Performed a spatial epidemiological study to explore variations and distribution } \\
\text { of patients with diabetes. }\end{array}$ \\
\hline
\end{tabular}


Tuberculosis) was mapped across Kuwait's governorates (Aziz, 1990).

\section{Community health profiling}

Only one study fell into this category (Murad, 2008a). The authors reported on the development of a GIS-based epidemiological application to study the distribution of diabetes in Jeddah, KSA. The work involved modelling the spatial variations in the distribution of people living with diabetes in the city.

\section{Discussion}

\section{Main findings}

Our review revealed 24 refereed papers published in the last two decades with the majority of these papers concerning the KSA; mostly $(n=7)$ originating from King Abdulaziz University, a public university in Jeddah. Only one paper was identified from Kuwait and another from the UAE. Coverage of the remaining GCC states was not evident in the literature indicating that the use of GIS in GCC states needs to increase to keep pace with the levels reported elsewhere (Nykiforuk and Flaman, 2011; Shaw and McGuire, 2017). Compared with current evidence, the low number of studies about the research topic in the region could indicate low levels of maturity concerning the use and adoption of GIS for health in the GCC. This could be attributed to the low numbers of research projects focused on the use of GIS to understand place and health. When compared with earlier studies outside of the GCC, GIS was used in the healthcare domain in significantly more reports than observed here for the GCC (Nykiforuk and Flaman, 2011; Shaw and McGuire, 2017).

Despite oil-based wealth, capacity-limited GCC health care systems are stressed with increasing demands for services due to a growing immigrant population, rising rates of NCDs (Mabry et al., 2016; Khoja et al., 2017), and road traffic injuries affecting people of all ages (Al Makadma 2017). While the GCC states have established public health systems, there is a need to better organize and integrate the various components of these systems (Khoja et al., 2013). GIS is a critical enabler that aids policymakers to make evidence-based and informed location-specific interventions (Fradelos et al., 2014). GIS has been used to assess the accessibility to health care facilities due to their importance on the overall population health and management of NCDs (Kapwata and Manda, 2018). GIS can play a role by offering unparalleled capabilities to aide in the integration of the public health system components via identifying, describing, analysing, predicting, and visualizing issues related to place and health ultimately informing and guiding health policies (Nykiforuk and Flaman, 2011). Examples include improved public health campaign targeting, location specific interventions based on clusters of NDCs, and healthy eating programs targeted at locations with higher rates of obesity. However, the evidence from the GCC about how GIS can be applied to guide policy and practice relative to public health is still in its infancy as indicated from these results.

Since the GCC states share many common features including similar cultural backgrounds, the rapid growth of fast-food restaurants, hot climate, and limited access to sporting venues ( $\mathrm{Ng}$ et al., 2011), the use of GIS can help better understand this context. For example, GIS can be used to identify, analyse and map unhealthy behaviours (e.g. smoking, excessive consumption of alcohol, unhealthy dietary practices, and inadequate physical activities) in a particular population or specific region (Silva, 2016). Therefore, GIS can be used to decide where and how to implement and subsequently evaluate the impact of specific, targeted public-health interventions.

Our results indicate that the health access and planning category accounted for the majority of studies applying GIS. These studies explored the distribution of primary health care resources and geographic barriers to accessing them in a timely manner. The need for such studies is arguably explainable by the fact that many of the GCC health care systems today face financial hardships to maintain the status-quo and strive for higher efficiency and improved access to their health system (Alkhamis et al.,2014).

Studies falling under health risk analysis naturally focused on communicable and infectious diseases such as dengue fever. Interestingly, half of the studies in this category were from Jeddah, $\mathrm{KSA}$, the closest major city to Makkah (approximately 85 Kilometres away), the holy city of Islam and host of the annual pilgrimage, "Hajj". We argue that these studies were influenced by the fact that Hajj is the world's largest annual mass gathering event that brings people from across the world to a small area of about 12 kilometres that is disease-prone, which in turn promotes the transmission of infections (Salmon-Rousseau et al., 2016). Hajj lasts for 5 days, however, many of the pilgrims usually travel for longer (Mughal et al., 2018). Evidence denotes that mass gatherings similar to Hajj (e.g. sports competitions and refugee camps) can be conducive to the transmission of infectious diseases such as invasive meningococcal disease (Muttalif et al., 2019).

However, as indicated by our results, few studies have investigated the impact of environmental changes experienced by the region (i.e. climate change and greenhouse gas emissions) on public health. Only one study identified in this review (Al-Ahmadi and Al-Zahrani, 2013a) investigated health (cancer rates) as a function of the physical environment (exposure to polluted air). Given the climate changes across the globe, and the GCC's vulnerability to increased frequency of extreme temperatures due to its hyper-arid desert climate (Ahmadalipour and Moradkhani, 2018; Alahmad et al., 2020), more studies are needed to examine relationships between the environment and health. It is unsurprising that NCDs were the focus of studies in the disease surveillance category. NCDs account for more than two-thirds of total disability-adjusted life years in the Middle East and North Africa region, including the GCC (Asbu et al., 2017). Interestingly, only one study was categorized in the community health profiling category and focused on diabetes (Murad, 2008a). Such studies are useful to explore the required services for particular diseases or conditions and to inform policy-based interventions.

The results of this study indicate a deficiency of published evidence regarding the use of GIS in support of public health in GCC states. More effort is needed in applying GIS technology to understand the interplay between "place and health" in the unique conditions of the GCC states. Given unique cultural and ethnic influences, place and health relationships in the GCC stand to be different from those in other industrialised nations. Understanding differences and similarities to other countries is important to undertake location-based initiatives to address urgent public health needs.

\section{Study strengths and limitations}

Significant contributions related to the use of GIS for health applications may exist but could not be captured in this study due 
to being published in languages other than English (i.e. Arabic), or reported elsewhere (e.g. conference proceedings, reports, or newspaper articles). Due to the nature of scientific publications in general, there is an inescapable publication bias with a tendency to report positive results only (Wass, 2019). As a result, there might be other work that could not be included in this study because it was not published, or in the format of non-peer-reviewed technical reports. Although we applied a comprehensive search strategy, there is a small probability that some relevant studies were not captured due to evaluating their titles and abstracts only during the screening phase. Additionally, some studies do not explicitly reference the use of GIS and hence would not be detected through our methods.

\section{Conclusions}

Connecting place and health is essential to gain better and deeper insights into how the environment and place in which people live in affects their health. GIS is a key tool that has the potential to positively improve public health practices through understanding and applying interventions based on the knowledge of how context impacts health, both directly and indirectly, via complex interactions with intermediary factors. This study highlighted the small number of GIS applications for public health purposes across the GCC states, which compromised planning and strategic decision making in health risk analysis, disease surveillance, community health profiling and health services provision. GCC states face a myriad of socioeconomic challenges and must reform their health care systems to improve their operating environment, reduce costs and increase quality of care. GIS can be a catalyst by providing an evidence-base for effective interventions.

\section{References}

Adegboye OA, Gayawan E, Hanna F, 2017. Spatial Modelling of Contribution of Individual Level Risk Factors for Mortality from Middle East Respiratory Syndrome Coronavirus in the Arabian Peninsula. PloS One 12:e181215. doi:10.1371/journal.pone.0181215

Ahmadalipour A, Moradkhani H, 2018. Escalating Heat-Stress Mortality Risk Due to Global Warming in the Middle East and North Africa (MENA). Environ Int 117:215-25. doi:10.1016/j.envint.2018.05.014

Al Makadma, 2017. Adolescent Health and Health Care in the Arab Gulf Countries: Today's Needs and Tomorrow's Challenges." Int J Ped Adol Med 4: 1-8. doi:10.1016/j.ijpam. 2016.12.006

Alahmad B, Shakarchi AF, Khraishah H, Alseaidan M, Gasana J, et al., 2020. Extreme Temperatures and Mortality in Kuwait: Who Is Vulnerable? Sci of The Total Environ 732:139289. doi:10.1016/j.scitotenv.2020.139289

Al-Ahmadi K, Alahmadi S, Al-Zahrani A, 2019. Spatiotemporal Clustering of Middle East Respiratory Syndrome Coronavirus (MERS-CoV) Incidence in Saudi Arabia, 2012-2019. Int J Environ Res Public Health 16:2520. doi:10.3390/ijerph16 142520

Al-Ahmadi K, Al-Zahrani A, 2013a. $\mathrm{NO}_{2}$ and Cancer Incidence in Saudi Arabia. Int J Environ Res Public Health 10:5844-62. doi:10.3390/ijerph10115844

Al-Ahmadi K, Al-Zahrani A, 2013b. Spatial Autocorrelation of Cancer Incidence in Saudi Arabia. Int J Environ Res Public Health 10:7207-28. doi:10.3390/ijerph10127207

Al-Haifi AR, Al-Fayez MA, Al-Athari BI, Al-Ajmi FI, Allafi AR, et al., 2013. Relative Contribution of Physical Activity, Sedentary Behaviors, and Dietary Habits to the Prevalence of Obesity among Kuwaiti Adolescents. Food Nutr Bull 34:6-13. doi:10.1177/156482651303400102

Alkhamis AA, 2017. Critical Analysis and Review of the Literature on Healthcare Privatization and Its Association with Access to Medical Care in Saudi Arabia. J Infect Public Health 10: 258-68. doi:10.1016/j.jiph.2017.02.014

Alkhamis A, Hassan A, Cosgrove P, 2014. Financing Healthcare in Gulf Cooperation Council Countries: A Focus on Saudi Arabia. Int J Health Plan Manag 29:e64-82. doi:10.1002/ hpm. 2213

Al-Maamary HMS, Kazem HA, Chaichan MT, 2017. Climate Change: The Game Changer in the Gulf Cooperation Council Region. Renew Sustain Ener Rev 76:555-76. doi:10.1016/j. rser.2017.03.048

Al-Rubeaan KA, Youssef AM, Subhani SN, Ahmad NA, AlSharqawi AH, et al., 2013. A Web-Based Interactive Diabetes Registry for Health Care Management and Planning in Saudi Arabia. J Med Internet Res 15. doi:10.2196/jmir.2722

Alzahrani AG, Al Mazroa MA, Alrabeah AM, Ibrahim AM, Mokdad AH, Memish ZA, 2013. Geographical Distribution and Spatio-Temporal Patterns of Dengue Cases in Jeddah Governorate from 2006-2008. Transact R Soc Trop Med Hygiene 107: 23-9. doi:10.1093/trstmh/trs011

Arksey H, O’Malley L, 2005. Scoping Studies: Towards a Methodological Framework. Int J Soc Res Methodol 8:19-32. doi:10.1080/1364557032000119616

Asbu EZ, Masri MD, Kaissi A, 2017. Health Status and Health Systems Financing in the MENA Region: Roadmap to Universal Health Coverage. Glob Health Res Pol 2:25. doi:10.1186/s41256-017-0044-9

Aziz MM, 1990. Spatial Patterns of Exogenous Mortality in Kuwait. Geogr Rev Jpn 63:188-97. doi:10.4157/grj1984b .63 .188

Benziger CP, Roth GA, Moran AE, 2016. The Global Burden of Disease Study and the Preventable Burden of NCD. Glob Heart 11:393-7. doi:10.1016/j.gheart.2016.10.024

Chen S, Kuhn M, Prettner K, Bloom DE, 2018. The Macroeconomic Burden of Noncommunicable Diseases in the United States: Estimates and Projections. PLoS One 13:e0206702. doi:10.1371/journal.pone.0206702

Coffee N, Turner D, Clark RA, Eckert K, Coombe D, 2012. Measuring National Accessibility to Cardiac Services Using Geographic Information Systems. Appl Geogr 34: 445-55. doi:10.1016/j.apgeog.2012.01.007

Cozier YC, 2017. Invited Commentary: The Enduring Role of 'Place' in Health-A Historic Perspective. Am J Epidemiol 185: 1203-5. doi:10.1093/aje/kwx085

Cromley EK, McLafferty S, 2011. GIS and Public Health. New York, NY, USA: Guilford Press.

Daniel M, Moore S, Kestens Y, 2008. Framing the Biosocial Pathways Underlying Associations between Place and Cardiometabolic Disease. Health Place 14:117-32. doi:10.1016/j.healthplace.2007.05.003

Dietrich D, Dekova R, Davy S, Fahrni G, Geissbühler A, 2018. 
Applications of Space Technologies to Global Health: Scoping Review. J Med Internet Res 20:e230. doi:10.2196/jmir.9458

Dummer TJB, 2008. Health Geography: Supporting Public Health Policy and Planning. CMAJ: Can Med Assoc J 178:1177-80. doi:10.1503/cmaj.071783

Fletcher-Lartey SM, Caprarelli G, 2016. Application of GIS Technology in Public Health: Successes and Challenges. Parasitol 143:401-15. doi:10.1017/S0031182015001869

Fradelos EC, Papathanasiou IV, Mitsi D, Tsaras K, Kleisiaris CF, Kourkouta L, 2014. Health Based Geographic Information Systems (GIS) and Their Applications. Acta Inform Med AIM 22:402-5. doi:10.5455/aim.2014.22.402-405

Greer W, Sandridge AL, Al-Menieir M, Al Rowais A, 2005. Geographical Distribution of Congenital Heart Defects in Saudi Arabia. Annals Saudi Med 25:63-9. doi:10.5144/02564947.2005.63

Jaber SM, Ibbini JH, Hijjawi NS, Amdar NM, Huwail MJ, AlAboud K, 2013. Exploring Recent Spatial Patterns of Cutaneous Leishmaniasis and Their Associations with Climate in Some Countries of the Middle East Using Geographical Information Systems. Geospat Health 8:62. doi:10.4081/ gh. 2013.62

Jamal A, Rahman MT, Al-Ahmadi HM, Mansoor U, 2019. The Dilemma of Road Safety in the Eastern Province of Saudi Arabia: Consequences and Prevention Strategies. Int J Environ Res Public Health 17:157. doi:10.3390/ijerph17010157

Jia P, Cheng X, Xue H, Wang Y, 2017. Applications of geographic information systems (GIS) data and methods in obesity-related research. Obes Rev 18 (4): 400-11. doi:10.1111/obr.12495

Jokar Arsanjani J, 2017. Remote Sensing, Crowd Sensing, and Geospatial Technologies for Public Health: An Editorial. Int J Environ Res Public Health 14:405. doi:10.3390/ijerph1 4040405

Kapwata T, Manda S, 2018. Geographic Assessment of Access to Health Care in Patients with Cardiovascular Disease in South Africa. BMC Health Serv Res 18:197. doi:10.1186/s12913018-3006-0

Khoja T, Qidwai W, Ahmed MSH, Rawaf S, Nanji K, 2013. The Way Forward to Public Health in Gulf Cooperation Council (GCC) Countries: A Need for Public Health Systems and Law. Middle E J Fam Med 11:23-7. doi:10.5742/MEJFM.2013. 115267

Khoja T, Rawaf S, Qidwai W, Rawaf D, Nanji K, Hamad A, 2017. Health Care in Gulf Cooperation Council Countries: A Review of Challenges and Opportunities. Cureus 9:e1586. doi:10.7759/cureus.1586

Khormi HM, Kumar L, 2011. Modeling Dengue Fever Risk Based on Socioeconomic Parameters, Nationality and Age Groups: GIS and Remote Sensing Based Case Study. Sci Total Environ 409:4713-9. doi:10.1016/j.scitotenv.2011.08.028

Khormi HM, Kumar L, 2012. Assessing the Risk for Dengue Fever Based on Socioeconomic and Environmental Variables in a Geographical Information System Environment. Geospat Health 6:135. doi:10.4081/gh.2012.135

Khormi HM, Kumar L, Elzahrany RA, 2011. Modeling spatiotemporal risk changes in the incidence of dengue fever in Saudi Arabia: a geographical information system case study. Geospat Health 6:159. doi:10.4081/gh.2011.159

Khoury MH, Iademarco MF, Riley WT, 2016. Precision Public Health for the Era of Precision Medicine. Am J Prev Med 50:398-401. doi:10.1016/j.amepre.2015.08.031
Klautzer L, Becker J, Mattke S, 2014. The Curse of Wealth Middle Eastern Countries Need to Address the Rapidly Rising Burden of Diabetes. Int J Health Pol Manag 2:109-14. doi:10.15171/ijhpm.2014.33

Mabry R, Koohsari MJ, Bull F, Owen N, 2016. A Systematic Review of Physical Activity and Sedentary Behaviour Research in the Oil-Producing Countries of the Arabian Peninsula. BMC Public Health 16:1003. doi:10.1186/s12889016-3642-4

Makanga PT, Schuurman N, von Dadelszen P, Firoz T, 2016. A Scoping Review of Geographic Information Systems in Maternal Health. Int J Gynaecol Obstet 134:13-7. doi:10. 1016/j.ijgo.2015.11.022

Mansour S, 2016. Spatial Analysis of Public Health Facilities in Riyadh Governorate, Saudi Arabia: A GIS-Based Study to Assess Geographic Variations of Service Provision and Accessibility. Geo-Spat Inf Sci 19: 26-38. doi:10.1080/1009 5020.2016.1151205

Massoudi BL, Chester KG, 2017. Public Health, Population Health, and Epidemiology Informatics: Recent Research and Trends in the United States. Yearb Med Inform 26:241-7. doi:10.15265/IY-2017-035

Mattke S, Hunter LE, Magnuson M, Arifkhanova A, 2015. Population Health Management and the Second Golden Age of Arab Medicine. Rand Health Q 5:1.

Moher D, Liberati A, Tetzlaff J, Altman DG, PRISMA Group. 2009. Preferred reporting items for systematic reviews and meta-analyses: the PRISMA statement. PLoS Med 6:e1000097. doi:10.1371/journal.pmed.1000097

Mughal, Faraz, Carolyn A. Chew-Graham, and Ahmad Saad. 2018. Hajj: What It Means for General Practice. BJGP Open 2:bjgpopen18X101493. doi:10.3399/bjgpopen18X101493

Murad AA, 2004. Creating a GIS Application for Local Health Care Planning in Saudi Arabia. Int J Environ Health Res 14:185-99. doi:10.1080/0960312042000218606

Murad AA, 2007. Creating a GIS Application for Health Services at Jeddah City. Comput Biol Med 37:879-89. doi:10.1016/j. compbiomed.2006.09.006

Murad AA, 2008a. Creating a GIS-Based Epidemiological Application for Jeddah City. Int J Healthc Technol Manag 9:540-51. doi:10.1504/IJHTM.2008.020204

Murad AA 2008b. Defining Health Catchment Areas in Jeddah City, Saudi Arabia: An Example Demonstrating the Utility of Geographical Information Systems. Geospat Health 2:239. doi:10.4081/gh.2008.239

Murad, 2011. Creating a Geographical Information SystemsBased Spatial Profile for Exploring Health Services Supply and Demand. Am J Appl Sci 8:644-51. https://doi.org/10. 3844/ajassp.2011.644.651

Murad, 2012. Benchmarking the Location of Health Centers at Jeddah City: A GIS Approach. Benchmarking 19:93-108. doi:10.1108/14635771211218380

Murad, 2014. Using Geographical Information Systems for Defining the Accessibility to Health Care Facilities in Jeddah City, Saudi Arabia. Geospat Health 8:295. doi:10.4081/gh. 2014.295

Murad, 2018. Using GIS for Determining Variations in Health Access in Jeddah City, Saudi Arabia. Int J Geo-Inf 7:254. doi:10.3390/ijgi7070254

Musa GJ, Chiang PH, Sylk T, Bavley R, Keating W, 2013. Use of GIS Mapping as a Public Health Tool-From Cholera to 
Cancer. Health Serv Insights 6:111-6. doi:10.4137/HSI. S10471

Muttalif AR, Presa JV, Haridy H, Gamil A, Serra LC, Cané A, 2019. Incidence and Prevention of Invasive Meningococcal Disease in Global Mass Gathering Events. Infect Dis Ther 8:569-79. doi:10.1007/s40121-019-00262-9

Ng SW, Zaghloul S, Ali HI, Harrison G, Popkin BM, 2011. The Prevalence and Trends of Overweight, Obesity and NutritionRelated Non-Communicable Diseases in the Arabian Gulf States. Obes Rev 12:1-13. doi:10.1111/j.1467-789X.2010. 00750.x

Nykiforuk CIJ, Flaman LM, 2011. Geographic Information Systems (GIS) for Health Promotion and Public Health: A Review. Health Promo Pract 12:63-73. doi:10.1177/15248399 09334624

Ouzzani M, Hammady H, Fedorowicz Z, Elmagarmid A, 2016. Rayyan-a Web and Mobile App for Systematic Reviews. Syst Rev 5:210. https://doi.org/10.1186/s13643-016-0384-4

Salmon-Rousseau A, Piednoir E, Cattoir V, de La Blanchardière A, 2016. Hajj-Associated Infections. Med Maladies Infect 46:346-54. doi:10.1016/j.medmal.2016.04.002

Sepúlveda M, 2014. Public Health Informatics and the Public Health Workforce in an Era of Change. Am J Prevent Med 47:S386-387. doi:10.1016/j.amepre.2014.07.014
Shaw NT, McGuire SK, 2017. Understanding the Use of Geographical Information Systems (GIS) in Health Informatics Research: A Review. J Innov Health Inf 24:940. doi:10.14236/jhi.v24i2.940

Silva JP, 2016. Mapping Unhealthy Behavior Among Economically Active Men Using GIS in Suburban and Rural Areas of Sri Lanka. Asia-Pacific J Public Health 28:10S-16S. doi:10.1177/1010539515611723

Subhani SN, 2009. Use of Geographical Information System within Web-Based Saudi National Diabetes Registry. Int J Geoinf 5:27-32. Available from: https://proceedings.esri. com/library/userconf/health09/docs/monday/use_of_gis_within_web_based_diabetes_registry.pdf

Thiébaut R, Thiessard F, 2017. Public Health and Epidemiology Informatics. Yearb Med Inf 26:248-51. doi:10.15265/IY-2017036

Wass MN, Ray L, Michaelis M, 2019. Understanding of Researcher Behavior Is Required to Improve Data Reliability. GigaSci 8:giz017. doi:10.1093/gigascience/giz017

Yagoub MM, 2011. Geographic Information Systems (GIS) Application for Health: Case of al Ain (UAE). Int J Geoinf 7:21-8. Available from: https://www.researchgate.net/publication/232724615_Geographic_Information_Systems_GIS_App lication_for_Health_Case_of_Al_Ain_UAE 